\title{
Clinical and Radiologic Results of Endovascular Coil Embolization for Cerebral Aneurysm in Young Patients
}

\author{
Hyun Seok Park, MD', Soon Chan Kwon, MD', Shang Hoon Shin, MD², Eun Suk Park, MD', \\ Hong Bo Sim, MD', In Uk Lyo, MD'
}

Purpose: This study is an overview of the clinical and radiologic outcomes of endovascular coil embolization for cerebral aneurysm in patients aged 40 years and younger.

Materials and Methods: Between January 2008 and June 2011, 218 aneurysms were treated using endovascular coil embolization and followed up with cerebral angiography at least six months later. Twenty-one aneurysms occurred in patients aged 40 years and younger, while 197 occurred in 179 patients older than 40 years. The clinical and radiologic results were retrospectively analyzed and compared between the two groups using the modified Rankin scale scores and the modified Raymond scale.

Results: Follow-up cerebral angiography revealed two (9.5\%) major and two (9.5\%) minor recanalized aneurysms in patients aged 40 years and younger, and six $(3.0 \%)$ major and $35(17.7 \%)$ minor recanalized aneurysms in patients older than 40 years. However, the differences between the groups were not statistically significant. The preoperative and postoperative mean modified Rankin scale scores at time for follow-up angiography were 1.14 and 0.19 respectively for patients aged 40 years and younger, and 1.30 and 0.30 respectively for patients older than 40 years.

Conclusion: The younger patients had clinically favorable outcomes with tolerable angiographic followup results. More regular and long-term imaging follow-up is required for younger patients due to their longer life expectancy.

Key Words : Age groups; Cerebral aneurysm; Treatment outcomes; Coil embolization

\footnotetext{
'Departments of Neurosurgery and ${ }^{2}$ Radiology, Ulsan University Hospital, University of Ulsan College of Medicine, Ulsan, Korea Received March 6, 2013; accepted after revision May 16, 2013. Correspondence to: Soon Chan Kwon, MD, PhD, Department of Neurosurgery, Ulsan University Hospital, University of Ulsan College of Medicine, 290-3 Jeonha-dong, Dong-gu, Ulsan 682-714, Korea. Tel. 82.52.250.7139 Fax. 82.52.250.7138

E-mail: nskwon.sc@gmail.com

This is an Open Access article distributed under the terms of the Creative Commons Attribution Non-Commercial License (http://creativecommons.org/licenses/by-nc/3.0) which permits unrestricted non-commercial use, distribution, and reproduction in any medium, provided the original work is properly cited.
}

Endovascular treatment (EVT) has become an established procedure for treating intracranial aneurysms. Over the past 20 years, reports of this technique and its outcomes have been published by endovascular specialists [1-7]. In 2002, the results of the International Subarachnoid Aneurysm Trial (ISAT) demonstrated the clinical superiority of EVT over standard surgical treatment for ruptured intracranial aneurysm [7]. Some published articles have examined the efficacy of detachable coils for stabilizing occlusions and providing protection against the growth or regrowth of aneurysms and consequent bleeding 
[1-3]. The widespread use of detachable coils for endovascular coil embolization of intracranial cerebral aneurysms has made EVT mainstay of aneurysm treatment. Nonetheless, there have been few data in the outcomes of younger patients' EVT for intracranial cerebral aneurysms [2, $8-13]$. The purpose of this study was to provide an overview of the clinical and radiologic outcomes of endovascular coil embolization for cerebral aneurysm in patients aged 40 years and younger.

\section{MATERIALS AND METHODS}

\section{Patient Demographics}

Between January 2008 and June 2011, 294 cerebral aneurysms in 249 patients were treated by two neurointerventionalist (one neurosurgeon and one neuroradiologist) using endovascular coil embolization. Dissecting, fusiform, infectious or traumatic aneurysms were excluded. Of these, 218 aneurysms in 200 patients with follow-up angiography at least six months were included in this study. Twenty-one aneurysms (14 ruptured [66.6\%] and seven unruptured [33.3\%]) occurred in 21 patients aged 40 years and younger (mean age: 33.5 years; range: $27-40$ years). Of these, 13 patients were men, and eight were women. The mean angiography follow-up period was 9.3 months \pm 2.69 in the younger group. A total of 197 aneurysms (96 ruptured [48.7\%] and 101 unruptured [51.3\%]) occurred in 179 patients older than 40 years (mean age: 61.8 years; range: $41-84$ years). Of these, 70 patients were men, and 127 were women. The mean angiography follow-up period was 9.2 months \pm 2.54 in the older group.

In the younger group, ruptured aneurysm rate was higher than the other (Table 1). But, it was not statistically significant. The clinical and angiographic data of the 21 patients are summarized in Table 2.

\section{Procedure}

We performed coil embolizations for all cerebral aneurysm through the common femoral artery under general anesthesia. In case of aneurysms with wide necks or unfavorable shapes, we used the methods of double catheter, balloon or stent-assisted coil embolization. Patients with unruptured aneurysms electively underwent endovascular coil embolization, and patients with ruptured aneurysms underwent within 24 hours. After the completion of coil embolization, we divided the angiographic findings into three classes using the modified Raymond scale: complete occlusion, neck remnant, and residual aneurysm [12]. An aneurysm was classified as completely occluded when there was no contrast filling within the aneurysm. Aneurysms were classified as neck remnant when there was some contrast near the aneurysm neck. A residual aneurysm was determined when some contrast was seen in the aneurysm neck and dome.

\section{Angiographic and Clinical Follow-up}

We checked the follow-up cerebral angiography to disclose recanalization at least six months after treatment. We classified minor recanalization as minimal coil compaction at the aneurysm neck, and major recanalization as contrast filling within the dome of the aneurysm or significant coil compaction. We checked the clinical outcomes before the procedure and at follow-up angiography using the modified Rankin scale scores (mRS). Clinical outcomes were reviewed from clinical charts.

\section{Statistical Analysis}

All of data were analysed using Statistical Package for Social Sciences (SPSS version, 19.0, SPSS Inc., USA). Chi-square test was used to compare general characteristic frequencies. Fisher's exact test was used to compare aneurysm location frequencies and recanal-

Table 1. Patient Data

\begin{tabular}{|c|c|c|c|}
\hline Variable & $\leq 40$ years old & $>40$ years old & $p$ - value \\
\hline Number of patients & 21 & 179 & \\
\hline Age (years) ${ }^{*}$ & $33.5 \pm 6.5(27-40)$ & $62.5 \pm 21.5(41-84)$ & \\
\hline Sex (male/female) & $13 / 8$ & $70 / 1217$ & 0.033 \\
\hline Number of aneurysms & 21 & 197 & \\
\hline Ruptured/unruptured & $14 / 7(66.6 \% / 33.3 \%)$ & $96 / 101(48.7 \% / 51.3 \%)$ & 0.183 \\
\hline Mean angiography follow-up (months) & $9.3 \pm 2.69(6-32)$ & $9.2 \pm 2.54(6-38)$ & \\
\hline
\end{tabular}

*Mean age and standard deviation (range) 


\section{Coil Embolization for Cerebral Aneurysm in Young Patients}

ization rate between age group. Mann-Whitney U test was used to evaluate clinical outcome score between age group. Significance level was set as 0.05 .

\section{RESULTS}

\section{Aneurysm Location}

Among 21 aneurysms in young age group, there were 20 anterior circulation aneurysms and one posterior circulation aneurysms. The anterior communicating artery ( 8 aneurysms, $38.0 \%$ ), middle cerebral artery (MCA) (4 aneurysms, 19.0\%) and paraclinoid internal carotid artery (ICA) (3 aneurysms, 14.3\%), posterior communicating artery ( 3 aneurysms, 14.3\%) were frequent sites. Total of 197 aneurysms in other group, there were 189 anterior circulation aneurysms and 8 posterior circulation aneurysms. Almost aneurysm locations were not different between two groups, however the difference in the ICA bifurcation aneurysm rate was statistically significant between the two groups (Table 3). The distribution of all groups' aneurysm location was similar to a previous study [7].

\section{Immediate Angiographic Findings}

All immediate angiographic findings were evaluated and classified by an independent investigator. The initial angiographic outcomes for the aneurysms in patients aged 40 years and younger were complete occlusion in $18(85.7 \%)$ and neck remnant in three $(14.3 \%)$. There was no residual aneurysm. The initial angiographic outcomes for aneurysms in patients older than 40 years were complete occlusion in $179(90.8 \%)$,

Table 2. Patient Characteristics

\begin{tabular}{|c|c|c|c|c|c|c|c|c|c|}
\hline No. & Age/sex & Location & $\begin{array}{c}\text { Size } \\
\text { grade }\end{array}$ & $\begin{array}{l}\text { Fisher } \\
\text { grade }\end{array}$ & $\begin{array}{c}\mathrm{H}-\mathrm{H} \\
\text { angiography }\end{array}$ & $\begin{array}{l}\text { Time for F/U } \\
\text { angiography }\end{array}$ & $\begin{array}{c}\text { Result of F/U } \\
\text { mRS }\end{array}$ & $\begin{array}{c}\text { Preop } \\
\text { mRS }\end{array}$ & Post \\
\hline 1 & $\mathrm{M} / 29$ & A-com & $5.5 \times 6.6$ & 4 & 4 & 32 months & Min R & 4 & 0 \\
\hline 2 & $\mathrm{M} / 40$ & A-com & $4.5 \times 3$ & 2 & 2 & 6 months & SO & 2 & 0 \\
\hline 3 & $F / 39$ & right $\mathrm{P}$-com & $3.7 \times 2.4$ & 1 & 0 & 12 months & so & 2 & 0 \\
\hline 4 & $F / 28$ & A-com & $3.5 \times 2.5$ & 4 & 3 & 7 months & SO & 4 & 0 \\
\hline 5 & $\mathrm{M} / 39$ & A-com & $7.5 \times 6.4$ & 4 & 3 & 6 months & SO & 4 & 1 \\
\hline 6 & $F / 38$ & right $\mathrm{P}$-com & $3.5 \times 5.2$ & 2 & 2 & 6 months & SO & 0 & 0 \\
\hline 7 & M/39 & A-com & $4.0 \times 3.2$ & 4 & 3 & 6 months & SO & 0 & 0 \\
\hline 8 & $M / 32$ & A-com & $3.6 \times 3.4$ & 4 & 3 & 6 months & SO & 0 & 0 \\
\hline 9 & M/39 & right ICA bifurcation & $9.8 \times 5.8$ & 1 & 0 & 12 months & Maj R & 0 & 0 \\
\hline 10 & $\mathrm{M} / 34$ & left MCA & $6.5 \times 3.7$ & 3 & 2 & 6 months & SO & 1 & 0 \\
\hline 11 & $\mathrm{~F} / 40$ & right PCA & $9.7 \times 4.3$ & 3 & 2 & 6 months & Min R & 0 & 0 \\
\hline 12 & $\mathrm{M} / 37$ & right MCA & $1.3 \times 9.2$ & 4 & 3 & 7 months & SO & 1 & 1 \\
\hline 13 & $F / 36$ & right MCA & $7.8 \times 4.3$ & 4 & 4 & 6 months & SO & 0 & 0 \\
\hline 14 & $\mathrm{~F} / 37$ & A-com & $8.3 \times 5.1$ & 3 & 3 & 6 months & SO & 1 & 0 \\
\hline 15 & $\mathrm{M} / 40$ & A-com & $4.1 \times 4.2$ & 1 & 0 & 12 months & So & 0 & 0 \\
\hline 16 & $\mathrm{M} / 33$ & left MCA & $6.5 \times 3.7$ & 3 & 3 & 6 months & SO & 1 & 1 \\
\hline 17 & $\mathrm{M} / 33$ & left ICA paraclinoid & $4.9 \times 4.5$ & 4 & 3 & 6 months & Maj $R$ & 4 & 1 \\
\hline 18 & $\mathrm{~F} / 37$ & left ICA paraclinoid & $3.5 \times 2.5$ & 1 & 0 & 12 months & SO & 0 & 0 \\
\hline 19 & $\mathrm{M} / 27$ & left ICA paraclinoid & $4.0 \times 2.8$ & 1 & 0 & 12 months & SO & 0 & 0 \\
\hline 20 & $\mathrm{M} / 39$ & left ICA bifurcation & $5.5 \times 3.6$ & 1 & 0 & 12 months & SO & 0 & 0 \\
\hline 21 & $\mathrm{~F} / 40$ & right $\mathrm{P}$-com & $4.6 \times 3.7$ & 1 & 0 & 12 months & SO & 0 & 0 \\
\hline
\end{tabular}

Abbreviations: $\mathrm{H}-\mathrm{H}$ grade, Hunt and Hess grade; F/U,follow up; Preop mRS, Preoperative modified Ranking scale score; Post mRS, Postoperative mRS; A-com, Anterior communicating artery; ICA, Internal carotid artery; MCA, Middle cerebral artery; PCA, Posterior cerebral artery; P-com, Posterior communicating artery; SO, stable occlusion; Maj R, major recanalization; Min R, minor recanalization. 
neck remnant in $17(8.6 \%)$, and residual aneurysm in one $(0.5 \%)$. The differences between the two groups were not statistically significant.

\section{Follow-up Angiographic Findings and Retreatments}

Angiographic follow-up involved conventional angiography with DSA. All angiographic follow-up were evaluated and classified by an independent neuroradiologist. Recanalizations were noted in four aneurysms $(19.0 \%)$ in patients aged 40 years and younger. Two $(9.5 \%)$ were minor recanalizations of ruptured aneurysms and two $(9.5 \%)$ were major recanalizations, one in a ruptured aneurysm and the other in an unruptured aneurysm. The major recanalization was located at the bifurcation of the internal carotid artery in the unruptured aneurysm and at the internal carotid artery of the paraclinoid segment in the ruptured aneurysm. Additional coil embolizations were performed in these two cases. Recanalizations were noted in 41 aneurysms $(21.1 \%)$ for patients older than 40 years: $35(17.7 \%)$ were minor recanalizations and six $(3.0 \%)$ were major recanalizations. Of these minor recanalizations, 17 were ruptured aneurysms and 18 were unruptured aneurysms. All major recanalizations were in ruptured aneurysms: two located at the posterior communicating artery, three at the MCA, one at the basilar tip and one at the superior cerebellar artery. Additional coil embolizations were performed successfully with no complications in these six cases of major recanalization. The difference in recanalization rate between the younger and older groups was not statistically significant. Also, the difference in recanalization between ruptured and unruptured aneurysms was not statistically significant (Table 4).

\section{Clinical Outcomes}

No bleeding or rebleeding of cerebral aneurysms was detected during follow-up angiography. Procedurerelated complications occurred in two $(9.5 \%)$ out of 21 patients including one non-symptomatic angiographic thromboembolic event (4.7\%) and one non-symptomatic internal carotid dissection $(4.7 \%)$ in a patient under 40 years. There was no procedure-related major stroke or deaths. The preoperative mean mRS was 1.14, and the postoperative mean $\mathrm{mRS}$ was 0.19 at the time of follow-up angiographies of patients aged 40 years and younger. The preoperative mean $\mathrm{mRS}$ was 1.30 , and the postoperative mean mRS was 0.30 at the

Table 3. Location of Aneurysm ( $\mathrm{N}=218)$

\begin{tabular}{|ccccc}
\hline Location & $\leq 40$ years old & $>40$ years old & p-value & Total \\
\hline ICA & 8 & 76 & 1.000 & $84(38.5 \%)$ \\
\hline Paraclinoid ICA & 3 & 42 & 0.578 & $45(20.6 \%)$ \\
\hline P-com & 3 & 30 & 1.000 & $33(15.1 \%)$ \\
\hline AchoA & 0 & 2 & 1.000 & $2(0.9 \%)$ \\
\hline ICA bifurcation & 2 & 2 & 0.047 & $4(1.8 \%)$ \\
\hline ACA & 8 & 65 & 0.634 & $73(33.4 \%)$ \\
\hline A-com & 8 & 51 & 0.300 & $59(27.0 \%)$ \\
\hline Distal ACA & 0 & 14 & 0.371 & $14(6.4 \%)$ \\
\hline MCA & 4 & 48 & 0.789 & $52(23.6 \%)$ \\
\hline Posterior circulation & 1 & 8 & 1.000 & $9(4.1 \%)$ \\
\hline BA top & 0 & 5 & 1.000 & $5(2.2 \%)$ \\
\hline BA & 0 & 2 & 1.000 & $2(0.9 \%)$ \\
\hline VA & 0 & 1 & 1.000 & $1(0.5 \%)$ \\
\hline PCA & 1 & 0 & 0.096 & $1(0.5 \%)$ \\
\hline Total & 21 & 197 & & 218 \\
\hline
\end{tabular}

Abbreviations: ICA, Internal carotid artery; P-com, Posterior communicating artery; AchoA,Anterior choroidal artery; A-com, Anterior communicating artery; ACA, Anterior cerebral artery; MCA, Middle cerebral artery; BA, Basilar artery; VA, Vertebral artery; PCA, Posterior cerebral artery.

* calculated by Fisher's exact test 
Coil Embolization for Cerebral Aneurysm in Young Patients

Table 4. Recanalization Rate

\begin{tabular}{lccc}
\hline & $\leq 40$ years old & $>40$ years old & p-value \\
\hline Ruptured aneurysm & $3 / 14(21.4 \%)$ & $23 / 93(24.7 \%)$ & 1.000 \\
Unruptured aneurysm & $1 / 7(14.3 \%)$ & $18 / 104(17.3 \%)$ & 1.000 \\
Overall & $4 / 21(19.0 \%)$ & $41 / 197(20.8 \%)$ & 1.000 \\
\hline
\end{tabular}

Table 5. Clinical Outcomes

\begin{tabular}{lccc}
\hline Mean mRS & $\leq 40$ years old & $>40$ years old & $p$-value \\
\hline Preoperative & $1.14 \pm 1.56$ & $1.30 \pm 1.71$ & 0.837 \\
Postoperative & $0.19 \pm 0.40$ & $0.30 \pm 0.84$ & 0.934 \\
\hline
\end{tabular}

Abbreviations: $\mathrm{mRS}=$ modified Rankin scale score.

$p$-value was evaluated by Mann-Whitney $U$ test

follow-up angiographies of patients older than 40 years. The difference between groups was not statistically significant (preoperative $\mathrm{mRS}$, p-value: 0.837; postoperative $\mathrm{mRS}$, p-value: 0.934 ) (Table 5).

\section{DISCUSSION}

In our study, approximately $9.6 \%$ (21 of 218 ) of aneurysms in patients aged 40 years and younger were treated with coil embolization. $12.7 \%$ (14 of 110) of the ruptured aneurysms in patients aged 40 years and younger were treated by coil embolization.

A male dominance in young age group was noted compared with other group (Table 1), and this difference was statistically significant. The male dominance among patients with SAH has been described in childhood and adolescence, however the female ascendancy is described in adult group of patients [14, $15]$.

In aspect aneurysm location, ICA bifurcation aneurysm rate was statistically higher in young patients than in old patients (Table 3). Previous authors have noted that a vast majority of ruptured aneurysms in children and adolescents occur in the anterior circulation, especially in the ICA $[16,17]$. The ICA has a blood flow much greater than the anterior communicating artery and MCA. Such flow may exert intense hemodynamic stress on the arterial walls and thus, result in the formation of an aneurysm and rupture [16-18].

A previous study found that age had no significant impact on the recanalization of cerebral aneurysm [12], but many other factors influence recanalization, including aneurysmal height and neck width, aneurysm location, and ruptured aneurysm [9,12, 16-19]. In our study, the difference in recanalization between ruptured and unruptured aneurysms in each group was not statistically significant (Table 4). Previous studies reported wide variations in aneurysm recanalization rates ranging from zero to $42 \%$ [9, 12, 20-25]. Our study showed a $19 \%$ recanalization rate among patients aged 40 years and younger. When a major recanalization was found, we checked the cerebral angiography regularly. The primary treatment of choice for major recanalization in our hospital is recoiling. In present study, there were no statistically significant differences in recanalization between the two groups of patients (those aged 40 years and younger and those older than 40 years). Although our study showed a modest recanalization rate $(19 \%)$, there were no cases of bleeding or death during our follow-up.

Our study showed favorable clinical results of coil embolization for intracranial aneurysms with little procedure-related morbidity [9.5\% (two out of 21)] and no procedure-related deaths. Patients aged 40 years and younger had favorable outcomes on the preoperative and postoperative $\mathrm{mRS}$, but they were not statistically significant (preoperative mRS: 1.14 ; postoperative mRS: 0.19).

Although the rate of ruptured aneurysms in young patients was higher than other group $(14 / 21[\leq 40$ years old, 66.6\%] versus 93/197 [ $>40$ years old, $47.2 \%]$ ), difference of recanalization rate and clinical outcomes was not statistically significant. Although there was no definite recommendation of treatment for young patients with aneurysm, in general surgical clipping is preferred in young patients because of its durability and minimal surgical risk. Patients treated 
with endovascular therapy in the present study had good early clinical outcome with no perioperative mortality. Even though it has been a short term followup, there were no fatal procedural complications with endovascular treatment and complete aneurysm occlusion was noted in almost cases. Our results suggest that endovascular therapy can be a viable option in young patients with aneurysm as it seems to provide excellent clinical outcomes with high aneurysm occlusion rates and tolerable recanalization rates. But regular radiological and clinical follow up would be necessary, considering the remaining years of the patients.

Our study has some limitations. The first is the lack of an analysis of the relationship between recanalization and aneurysm location. As aneurysms at the bifurcation have higher recanalization rates than aneurysms at other locations, aneurysm location and hemodynamic changes could be related to recanalization rates [26]. Because of the small number of patients in our study, we could not analyze the significance of aneurysm location. The second limitation is that we did not evaluate the coil packing density after aneurysm coil embolization. Coil packing density is an important factor for recanalization but accurate calculation of coil packing density is very difficult because of the irregular aneurysm shape and 3D configuration. The third limitation is the short follow-up period of cerebral angiography. In our study, the mean angiographic follow-up was 9.3 months. So, long-term cerebral angiography follow-up is required for cerebral aneurysm patients undergoing coil embolization and we need to establish the relation between cerebral angiography follow-up and recanalization after complete coiling of an aneurysm.

In conclusion, the younger patients had clinically favorable outcomes with tolerable angiographic follow up results. Because they have a longer life expectancy, patients aged 40 years and younger treated by endovascular coil embolization should undergo more regular and long-term imaging follow-up.

\section{References}

1. Cognard C, Pierot L, Boulin A, Weill A, Tovi M, Castaings L, et al. Intracranial aneurysms: endovascular treatment with mechanical detachable spirals in 60 aneurysms. Radiology 1997;202:783792

2. Cognard C, Weill A, Castaings L, Rey A, Moret J. Intracranial berry aneurysms: angiographic and clinical results after endovascular treatment. Radiology 1998;206:499-510

3. Fernandez Zubillaga A, Guglielmi G, Vinuela F, Duckwiler GR. Endovascular occlusion of intracranial aneurysms with electrically detachable coils: correlation of aneurysm neck size and treatments results. AJNR Am J Neuroradiol 1994;15:815-820

4. Guglielmi G, Vinuela F, Dion J, Duckwiler G. Electrothrombosis of saccular aneurysms via endovascular approach. II. Preliminary clinical experience. J Neurosurg 1991;75:8-14

5. Guglielmi G, Viñ uela F, Duckwiler G, Dion J, Lylyk P, Berenstein A, et al. Endovascular treatment of posterior circulation aneurysms by electrothrombosis using electrically detachable coils. J Neurosurg 1992;77:515-524

6. Koebbe CJ, Veznedaroglu E, Jabbour P, Rosenwasser RH. Endovascular management of intracranial aneurysms: current experience and future advances. Neurosurgery 2006;59:S93-S102

7. Molyneux AJ, Kerr RS, Yu LM, Clarke M, Sneade M, Yarnold JA, et al. International Subarachnoid Aneurysm Trial (ISAT) of neurosurgical clipping versus endovascular coiling in 2143 patients with ruptured intracranial aneurysms: a randomised trial. Lancet 2002;360:1267-1274

8. Cognard C, Weill A, Spelle L, Piotin M, Castaings L, Rey A, et al. Long-term angiographic follow-up of 169 intracranial berry aneurysms occluded with detachable coils. Radiology 1999;212: 348-356

9. Fiorella D, Albuquerque FC, McDougall CG. Durability of aneurysm embolization with matrix detachable coils. Neurosurgery 2006;58:51-59

10. Murayama Y, Nien YL, Duckwiler G, Gobin YP, Jahan R, Frazee $\mathrm{J}$, et al. Guglielmi detachable coil embolization of cerebral aneurysms: 11 years' experience. J Neurosurg 2003;98:959-966

11. Ng P, Khangure MS, Phatouros CC, Bynevelt M, ApSimon H, McAuliffe W. Endovascular treatment of intracranial aneurysms with Guglielmi detachable coils: analysis of midterm angiographic and clinical outcomes. Stroke 2002;33:210-217

12. Raymond J, Guilbert F, Weill A, Georganos SA, Juravsky L, Lambert A, et al. Long-term angiographic recurrences after selective endovascular treatment of aneurysms with detachable coils. Stroke 2003;34:1398-1403

13. Thornton J, Debrun GM, Aletich VA, Bashir Q, Charbel FT, Ausman J. Follow-up angiography of intracranial aneurysms treated with endovascular placement of Guglielmi detachable coils. Neurosurgery 2002;50:239-249

14. Hourihan MD, Gates PC, McAllister VL. Subarachnoid hemorrhage in childhood and adolescence. J Neurosurg 1984;60: 1163-1166.

15. Wojtacha M, Bazowski P, Mandera M, Krawczyk I, Rudnik A. Cerebral aneurysms in childhood. Childs Nerv Syst 2001;17:37-41

16. Ostergaard JR. A long-term follow-up study of juvenile aneurysm patients. Acta Neurochir (Wien) 1985;77:103-109

17. Ostergaard JR. Aetiology of intracranial saccular aneurysms in childhood. Br J Neurosurg 1991;5:575-580

18. Pasqualin A, Mazza C, Cavazzani P, Scienza R, DaPian R. Intracranial aneurysms and subarachnoid hemorrhage in children and adolescents. Childs Nerv Syst 1986;2:185-190

19. Grunwald IQ, Papanagiotou P, Struffert T, Politi M, Krick C, Gül $\mathrm{G}$, et al. Recanalization after endovascular treatment of intracerebral aneurysms. Neuroradiology 2007;49:41-47

20. Lempert TE, Malek AM, Halbach VV, Phatouros CC, Meyers PM, Dowd CF, et al. Endovascular treatment of ruptured posterior circulation cerebral aneurysms: clinical and angiographic outcomes. Stroke 2000;30:100-110

21. Pandey AS, Koebbe C, Rosenwasser RH, Veznedaroglu E. 


\section{Coil Embolization for Cerebral Aneurysm in Young Patients}

Endovascular coil embolization of ruptured and unruptured posterior circulation aneurysms: review of a 10-year experience. Neurosurgery 2007;60:626-627

22. Roy D, Milot G, Raymond J. Endovascular treatment of unruptured aneurysm. Stroke 2001;32:1998-2004

23. Sluzewski M, van Rooij WJ, Rinkel GJ, Wijnalda D. Endovascular treatment of ruptured intracranial aneurysms with detachable coils: long-term clinical and serial angiographic results. Radiology 2003;227:720-724

24. Kawanabe Y, Sadato A, Taki W, Hashimoto N. Endovascular occlusion of intracranial aneurysms with Guglielmi detachable coils: correlation between coil packing density and coil compaction. Acta Neurochir (Wien) 2001;143:451-455

25. Kuether TA, Nesbit GM, Barnwell SL. Clinical and angiographic outcomes, with treatment data, for patients with cerebral aneurysms treated with Guglielmi detachable coils: a single-center experience. Neurosurgery 1998;43:1016-1025

26. Soeda A, Sakai N, Sakai H, Iihara K, Nagata I. Endovascular treatment of asymptomatic cerebral aneurysms: anatomic and technical factors related to ischemic events and coil stabilization. Neurol Med Chir (Tokyo) 2004;44:456-465 